\title{
ORÍGENES Y PRESENTE DEL FUNDAMENTALISMO JUDÍO
}

JAIME VÁNDOR

Universidad de Barcelona

Cuando, en la primavera del año pasado, uno de los directivos de la barcelonesa "Fundació Joan Maragall - Cristianisme i Cultura", el Dr. Pere Lluís Font, me habló del proyecto de un simposio sobre los diferentes fundamentalismos y me preguntó si podía contar conmigo para contribuir con una comunicación sobre el fundamentalismo judío, por de pronto me chocó esta denominación, y me hice la pregunta: «¿Existe realmente algo que podamos denominar así?».

Entre los judíos, a nuestros extremistas religiosos nunca los hemos designado de este modo. Los llamamos ultrarreligiosos o ultraortodoxos, y éste es también el nombre que les da la prensa no hebrea. Tanto es así, que la Encyclopaedia Judaica, editada en inglés en Jerusalén, en sus veinte primeros tomos que son los que yo poseo y que llegan hasta el año 1982, ni siquiera da entrada a esta voz. Por ello, por una parte me dirigí al agregado cultural de la Embajada de Israel, Sr. Ygal Palmor, con el ruego de que me aclarase si a los extremistas ortodoxos se les podía considerar fundamentalistas; por otra parte pedí a los organizadores del simposio que me permitiesen hablar el último día, tras haber escuchado a los restantes ponentes, para saber si, en vista de los fenómenos que caracterizan a los fundamentalismos de otras religiones, el extremismo judío de origen religioso podía considerarse como tal.

La respuesta es que sí. Es más, tal postura ideológica se remonta a más de doscientos años de antigúedad, cuando, con la aparición de la Haskkala o Ilustración judía por obra de Moses Mendelssohn y de su círculo innovador, que bien podemos llamar heterodoxo, 
dicho movimiento fue rechazado de plano por la ortodoxia, debido a su para entonces inaudito alejamiento de la tradición.

Lo que caracterizaba, y caracteriza todavía hoy al judaísmo ortodoxo, es su gran apego a la tradición, su amorosa fidelidad a las normas y reglas heredadas, milenarias sin duda, ya que se remontan al Talmud y a los midrasîm (y considérese que el Talmud terminó de redactarse en el año 500 de nuestra era). Textos que a su vez recogen exégesis, normas, usos y costumbres de siglos anteriores, hasta alcanzar la tradición oral viva de los últimos siglos bíblicos - me refiero, como es obvio, a la Biblia hebrea que fuera del judaísmo se denomina Antiguo Testamento-. La parte del Talmud que recoge los textos normativos de la conducta, así como el material jurídico disperso en la vasta compilación de este nombre, recibe la denominación de Halaka $a$, concepto que, al margen de la etimología, podemos traducir aproximadamente por "tradición". La Halaka $a$ rige la vida del judío estrictamente obsevante hasta en los más pequeños detalles de su vida diaria. Ya en los siglos XVII y XVIII formaba parte de la tradición que el judío limitase su interés intelectual casi exclusivamente a los estudios judaicos. Los casos de espíritus inquietos o curiosos que se saltaban esta norma, como un Baruk Spinoza o Uriel Da Costa, eran excepcionales.

Si tuviéramos que poner una fecha como indicativa del nacimiento de la pugna entre los maśkílim o ilustrados y la ortodoxia, apuntaríamos la del año 1778 , y a partir de ahí toda la década posterior, pues es cuando Mendelssohn, haciendo caso omiso de las prohibiciones de la tradición, inicia su traducción de la Biblia al alemán para uso de judíos, que editará en letras hebreas y con un comentario en hebreo. Las razones del escándalo que esto levantaba en círculos ortodoxos eran: 1) La tradición no permitía la traducción de las Escrituras Sagradas, pues se consideraba una profanación del texto revelado. 2) En sus comentarios Mendelssohn omitía las enseñanzas talmúdicas.

Pronto la Haśkalâ, Ilustración, aportaba las siguientes novedades que podemos añadir a las ya mencionadas: 3) Apertura frente al hermetismo, emancipación del área sinagogal, modernización en costumbres e indumentaria, afán de enriquecer a los judíos con la cultura europea y las ciencias profanas; todo esto en un momento en que la inmensa mayoría de los judíos vivía todavía encerrada en ghettos. 4) Postergación del Talmud frente a la Biblia hebrea, pres- 
cindiendo de la mayoría de los comentaristas cuya obra hubieran acumulado los siglos. 5) Postergación del idioma yiddish, dando primacía al alemán y al hebreo. Este se propone como apto y legítimo para todos los usos, lo que era casi una provocación, pues el uso multisecular sinagogal y de estudio de textos sagrados había sacralizado el hebreo hasta el punto de que el judaísmo tradicional veía en su posible uso cotidiano una profanación. (Digamos de paso que todavía quedan reductos ultrarreligiosos en Jerusalén, París, Amberes, Nueva York, etc. que rechazan el uso del hebreo como idioma de comunicación para la vida diaria).

Como es natural, la Haśkalâ se tuvo que enfrentar desde el primer momento con los sectores tradicionales, los cuales veían algunas de sus convicciones más sagradas e inveteradas puestas en entredicho de la noche a la mañana por unos innovadores irrespetuosos que en la mayoría de los casos ni siguiera tenían formación rabínica.

Otra corriente innovadora, pero ésta originada desde el campo de la fe, fue el hasidismo, una especie de pietismo místico antiintelectual y antiacadémico, muy fértil, que en sus inicios también se las tuvo que ver con la ortodoxia, pero que, con el paso de los tiempos y frente al enemigo común que es el descreimiento moderno, acabó por fundirse con en judaísmo tradicional, enriqueciéndolo, si bien también anquilosándose a la larga.

A partir del siglo XIX encontramos en el judaísmo las siguientes tendencias o corrientes ideológicas principales: ortodoxos -o sea los más estrictos-, conservadores, reformados o liberales, y finalmente los agnósticos o ateos, para los cuales el judaísmo significa, más que una religión, la pertenencia a un pueblo y fidelidad a su historia y su tradición ética. Los ortodoxos se oponen a todos los demás y se consideran los únicos judíos auténticos, legítimos, por decirlo así. A tenor de lo escuchado en los días anteriores, estos ortodoxos pueden ser considerados fundamentalistas en lo doctrinal. Los más radicales siguen prefiriendo el yiddish al hebreo, son refractarios a las innovaciones axiomáticamente y hasta en lo más nimio, temen la contaminación de la cultura occidental, veneran a su rabino carismático a cuyo juicio se someten incondicionalmente, y complen escrupulosamente todas las leyes, alimentarias, higiénicas, sabáticas, etc., que son innumerables.

Los ortodoxos perciben todo cambio como una contaminación, 
como una amenaza a la integridad de la fe, basándose en el hecho cierto de que sólo gracias a la Biblia, así como a la tradición y a la fidelidad estricta a las normas heredadas, sobrevivió el judaísmo a la confrontación con la cultura helenística primero, la del Imperio romano y de su civilización después, y finalmente, los dos mil años de diáspora. Pero se han quedado anclados en el Sulhan 'Arûk, última codificación halákica, obra de mediados del siglo XVI, sin querer ver que el mundo ha evolucionado infinitamente desde entonces, con el resultado de que el tradicional "cerco alrededor de la Ley" ya no conserva a los judíos dentro de la fe y la práctica religiosa, sino, bien al contrario, ha alejado a la mayor parte de ellos de la ortodoxia; los ha colocado fuera del "cerco" y convirtió a éste en un reducto que impide la adaptación de las costumbres a los nuevos tiempos. En contra de lo que afirman los ortodoxos, lo cierto es que la auténtica tradición judía, al menos desde las postrimerías de los tiempos bíblicos, ha sido la de la coexistencia de posturas religiosas y de tendencias ideológicas diferentes, como podría probarse con multitud de ejemplos desde los tiempos de Jesús, pasando por toda la Edad Media, hasta el mismo instante, relativamente moderno, del surgimiento del hasidismo. Un pluralismo en el que la tradición mantenía viva la fe, pero sin excluir la flexibilidad necesaria para que el pensamiento incorporase formas y elementos nuevos.

La influencia de la ortodoxia era naturalmente limitada en la diáspora, donde los judíos constituían una minoría en cada país. Grupos judíos podían desautorizarse mutuamente, pero carecían de autoridad legal para imponer normas o criterios.

La situación cambia por completo a partir del momento en que los judíos logran poseer un Estado propio. En 1948 nace Israel, Estado soberano, con una vida parlamentaria, partidos políticos, y la posibilidad -o mejor necesidad- de legislar. Se fortalece la militancia ortodoxa, y se politiza mediante la creación de partidos religiosos que nunca tendrán mayor relevancia numérica si contamos a los votantes. Pero sí la tendrán política, y extraordinaria, pues en Israel acabarán por predominar dos bloques principales, el laborismo, y frente a él lo que podríamos llamar con ciertas reservas la derecha que tras sucesivos cambios, incluso de denominación, cristalizó en lo que ahora conocemos con el nombre de Likkud.

La importancia de dichos partidos religiosos consiste, ya desde 
hace décadas, en que, para que uno de los dos partidos grandes tenga el número de votos suficiente para poder gobernar sin formar coalición con el otro, tiene que buscar la alianza con los pequeños partidos religiosos que para ello exigen determinadas prebendas. En principio se abstienen de interferirse en la política exterior, a cambio de formar parte del gobierno con las carteras de Interior y de Educación, además de la de Cultos. Por las imperfecciones del sistema democrático y siempre valiéndose de la amenaza de retirarse del gobierno con lo que ocasionaría la caída de éste, han logrado imponer una larga serie de leyes de origen religioso, cuyo papel para la vida cotidiana de la sociedad es tan decisivo que, sin que el Estado israelí sea teocrático ni mucho menos, la mayoría de la población, que es laica y ajena a la ideología ortodoxa, se ve limitada cotidianamente en su libertad por prescripciones de todo tipo. Leyes sabáticas que afectan a la circulación, a los servicios públicos, a la navegación y a la aviación; leyes alimentarias que afectan a la hostelería, a los mercados y a la industria, leyes matrimoniales y de divorcio (en Israel no existe el matrimonio civil). Exenciones por alegato de escrúpulos de conciencia que establecen, por tanto, diferencias en la aplicación de la ley entre los cuidadanos, por ejemplo, en cuanto al cumplimiento del servicio militar de las muchachas o en cuanto a efectuar una autopsia si los allegados no dan su consentimiento. He mencionado sólo algunos de los ejemplos más sencillos. Otros muchos son sumamente complejos, como los ligados a la famosa ley halákica, según la cual sólo se reconoce como judío al que es hijo de madre judía, no siendo reconocida la religión por vía paterna.

Muchas de estas leyes son del todo anacrónicas y difícilmente aceptables en una sociedad moderna, por ende urbana, industrial, y precisamente con un nivel de tecnología e investigación sumamente avanzado. Leyes que en parte ni figuran aún en el Antiguo Testamento y se basan en interpretaciones muy posteriores de determinados versículos. La presión religiosa, contra la cual se han fundado diversas ligas y sociedades, ha llevado a muchos indiferentes en materia de religión a perder esta indiferencia, y a aborrecer, odiar incluso en muchos casos, por impotencia, a sus conciudadanos más piadosos que a lo mejor políticamente ni siquiera votan a los partidos religiosos y carecen de toda culpa en la situación. Las posturas se han polarizado y desde finales de los años setenta se 
producen en Israel frecuentes enfrentamientos callejeros, agresiones, etc., bien entre judíos ortodoxos y judíos que allí para simplificar llaman laicos, bien entre judíos ultraortodoxos y la misma polícía israelí. Un estado de violencia latente cuya explosión sólo se ve contenida por el peligro compartido frente al enemigo común. ¿Pero qué pasará cuando se haga la paz con los países vecinos y se llegue a un modus vivendi pacífico con la minoría palestina del interior?

Los extremistas ortodoxos son relativamente pocos, pero sus desafueros llenan los peródicos. Sistemáticamente cortan las calles de sus barrios los sábados, con cadenas, para evitar la circulación rodada, apedrean coches, destruyen las paradas de autobús que llevan anuncios a su juicio pecaminosos, pueden llegar a provocar incendios o profanar tumbas, las de los mismos líderes laboristas fallecidos, como la de Golda Meir. Han llegado a desenterrar el cuerpo de una mujer que yacía en un cementerio judío y la cual, según su criterio de la halaḳâ, no era judía. Pueden llegar a ser peligrosos, aunque nunca tienen por objeto atentar contra la vida que, al menos por ahora, les parece sagrada.

Con todo, estos que podríamos llamar fundamentalistas, están muy desunidos. Las diferentes sectas hasídicas se niegan mutuamente, en Israel o en la diáspora (caso de los adeptos de las dinastías de «rebbes» de Lubavitch, Satmer o Belz). Más curiosa es la oposición radical entre dos grupúsculos ultraortodoxos. Unos, los llamados "Fieles del Templo», que aceptan el Estado de Israel como legítimo, luchan por la reconstrucción del Templo en la «Explanada de las Mezquitas", precisamente donde se hallan la mezquita de El Aqsa y la de la Roca, impropiamente llamada de Omar, lugares santos de primer orden para el Islam. Otros fanáticos, los «Guardianes de la Ciudad", son antisionistas en pleno Jerusalén, y no reconocer el Estado de Israel por haberse anticipado a la llegada del Mesías. Como es obvio, la construcción del Tercer Templo les parece una herejía. Éstos son aliados de los árabes, les pasan información y son enemigos declarados del Estado que consideran sacrílego y como obra del demonio.

Para terminar, algunas palabras acerca del futuro, quizá menos pesimistas de lo que cabría esperar a tenor de lo expuesto. A diferencia de los países musulmanes, Israel es una democracia desde el mismo día de su creación, y los ultraortodoxos no tienen la menor posibilidad de alcanzar el poder, cosa que por supuesto 
desean por encima de todo, para implantar la ley tradicional según su propio criterio a la totalidad del judaísmo. Pero los ortodoxos no alcanzan ni un tercio en todo el mundo judío, sin olvidar que la inmensa mayoría de este tercio es moderado y pacífico. En Israel los partidos religiosos no superan el $15 \%$ de los votos. El país ha vivido unas décadas de fuerte implantación de la enseñanza religiosa en las escuelas; el sentimiento religioso aumentó, en parte por el desgaste de los ideales socialistas de la generación de los pioneros, y en parte por la impresión causada por la Guerra del Yôm Kippûr (1973), única vez en la que Israel vio por unas horas peligrar su existencia. Ello dio a los extremistas una mayor fuerza, con exigencias desproporcionadas en relación a su número. Actualmente la tendencia propende a variar, gracias a la inmigración masiva de los judíos de la ex Unión Soviética, por ahora unos 350.000 , lo que previsiblemente redundará en el fortalecimiento del laicismo.

En cuanto al Ejército, desde la creación del Estado, siempre se ha abstenido de intervenir en la política. En su seno se da tanto el maximalismo - nacionalistas que desean engrandecer Israel anexando territorios-, como la tendencia contraria, de devolver tierras a cambio de paz. Pero ni unos ni otros tienen tintes fundamentalistas, tanto menos cuanto que los jóvenes religiosos que estudian en yěši bôt $\underline{t}$ están exentos del servicio militar.

Parte de las facciones agresivas del flanco ortodoxo viene financiado por comilitones de los Estados Unidos. Su influencia disminuiría de llegarse a un entendimiento, si no ya con Siria y el Líbano, al menos con los palestinos del interior. Pues si se pudiesen reducir los enormes gastos militares del país, también disminuiría la presión que, mediante la economía, ejercen los judíos más religiosos de los Estados Unidos sobre la política interior del país: me refiero a la legislación que, como se ha dicho, favorece a las sectas religiosas, a veces a través de los presupuestos regulares del Estado, a veces con partidas de dinero que los ministerios ideológicamente afines destinan bajo mano a las escuelas talmúdicas, contraviniendo la voluntad democráticamente expresada por la mayoría de la población. Con ello se lograría también que desapareciera la lamentable animadversión que los ortodoxos despiertan en gran parte de la población.

En resumen, el fundamentalismo judío suena mucho, pero lleva poca agua. Hoy por hoy Israel es una sociedad abierta, en el 
sentido que Karl Popper da a esta expresión: sociedad en la que es posible mantener abierta la mente a la hora de enjuiciar los valores. Hasta algunos tradicionalistas ven clara la conveniencia de mantener separados los espacios correspondientes a religión y Estado. Así Abraham Burg, diputado laborista, ciertamente ortodoxo, que al proponer una resolución en este sentido a su partido, dijo algo que en nuestro país hemos vivido y quizá aprendido: «la cooperación entre religión y Estado acaba por corromper a ambos».

\section{RESUMEN}

Como respuesta a la pregunta de si puede llamarse fundamentalismo a cierta ortodoxia judía, cuyos adeptos habitualmente se denominan no fundamentalistas sino ultrarreligiosos, se describen los distintos rasgos que la caracterizan. Sus inicios pueden enmarcarse en la confrontación del movimiento de la Haśkala con el inmovilismo conservador. Pese a su número reducido, ejercen una considerable influencia en el Estado de Israel, donde las posturas pro y antirreligiosas se han venido radicalizando en las últimas décadas hasta convertirse en un peligro para la convivencia. Tal violencia latente puede aflorar a la superficie una vez que la situación política del Estado en la región quede estabilizada.

\section{SUMMARY}

As an answer to the question if certain Jewish orthodoxy, whose members are called ultra-religious, it can be considered a sort of fundamentalism, the different features of that group are described. Its beginnings can be found in the confrontation between the Haskala movement and the conservatism. Although its number is not large, this group exerts a considerable influence in the State of Israel, where the pro and con religious positions have been radicalizing in the late decades up to becoming a danger for social life. Such a violence can rise the moment the political situation in the region could be stabilized. 